\title{
DESINFORMAÇÃO E COMPORTAMENTO INFORMACIONAL NAS MÍDIAS SOCIAIS: A DIVULGAÇÃO CIENTÍFICA NA PREVENÇÃO AO NOVO CORONAVÍRUS
}

\author{
DISINFORMATION AND INFORMATION BEHAVIOR IN \\ SOCIAL MEDIA: SCIENCE COMMUNICATION FOR \\ PREVENTION OF THE NOVEL CORONAVIRUS
}

\author{
Maurício de Vargas Corrêaa \\ Sônia Elisa Caregnatob
}

\begin{abstract}
RESUMO
Introdução: O clima de insegurança sobre a pandemia de Covid-19, a carência de informações precisas e o uso crescente das tecnologias de informação e comunicação parecem ter contribuído para impulsionar a produção e circulação de informações enganosas nas mídias sociais. Objetivo: O presente estudo teve por objetivo caracterizar as práticas discursivas associadas ao "Vídeo do álcool gel no WhatsApp é mentira" e identificar expressões do comportamento informacional nos comentários ao vídeo. Metodologia: A análise de conteúdo foi escolhida como método de pesquisa devido às características do material empírico e o foco sobre os significados emergentes. Resultados: No processo de análise, foram identificadas dez práticas discursivas relacionadas ao "Vídeo do álcool gel no WhatsApp é mentira", representadas pelas categorias opinar, ironizar, relatar, felicitar, agradecer, perguntar, engajar, contribuir, apoiar e solicitar. A categoria opinar foi a mais expressiva, com $50 \%$ das unidades de análise, sugerindo que a formação de opinião ou o julgamento sobre o conteúdo publicado é um aspecto relevante para os usuários. Expressões compatíveis com os comportamentos de busca, compartilhamento, avaliação e uso da informação foram observadas nas categorias relatar, perguntar, engajar, contribuir e solicitar, bem como as subcategorias elogio, convergência e crítica. Conclusões: Conclui-se que a caracterização das práticas discursivas expressas nos comentários permitiu a identificação do comportamento informacional em relação ao vídeo e das formas de engajamento com o conteúdo publicado no YouTube.
\end{abstract}

a Doutorando em Comunicação e Informação no Programa de Pós-Graduação em Comunicação da Universidade Federal do Rio Grande do Sul (UFRGS). BibliotecárioDocumentalista na Universidade Federal do Rio Grande do Sul (UFRGS). mauricio.correa@ufrgs.br.

b Doutora em Information Studies pela University of Sheffield, Inglaterra. Docente no Programa de Pós-Graduação em Comunicação e no Programa de Pós-Graduação em Ciência da Informação da Universidade Federal do Rio Grande do Sul (UFRGS). sonia.caregnato@ufrgs.br. 
Descritores: Desinformação. Comportamento informacional. Divulgação científica. Mídias sociais.

\section{INTRODUÇÃO}

Em dezembro de 2019, na cidade de Wuhan, na China, autoridades de saúde pública relataram diversos casos de síndrome respiratória aguda grave, cujo agente causador foi identificado pelos cientistas chineses como uma nova espécie de coronavírus. O surto pelo Coronavírus da Síndrome Respiratória Aguda Grave 2 (SARS-CoV-2) se espalhou rapidamente pelo território chinês, alcançando outros países da Ásia, Europa, Austrália, África e América (EUROPEAN CENTRE FOR DISEASE PREVENTION AND CONTROL, C2020) em um curto intervalo de tempo e levando a óbito milhares de pessoas.

O surgimento da pandemia pelo novo coronavírus trouxe incertezas à população em geral e às autoridades competentes. Dúvidas sobre a origem do vírus, formas de contágio, medidas de prevenção, modalidades de tratamento, produção de vacinas, eficácia do distanciamento social e a resposta do sistema de saúde à pandemia foram alguns dos temas que causaram controvérsias nos âmbitos político, sanitário, científico, midiático e social. O clima de insegurança, a carência de informações precisas e o uso crescente das tecnologias de informação e comunicação parecem ter contribuído para impulsionar a produção e circulação de informações enganosas relacionadas à Covid-19.

No final de fevereiro de 2020, circulou pelo aplicativo WhatsApp um vídeo de um homem autodeclarado químico autodidata que contesta a eficácia do álcool em gel 70\% na eliminação do coronavírus e sugere a substituição do produto por vinagre para essa finalidade. O conteúdo repercutiu negativamente em diversos sites da internet e entidades científicas e profissionais refutaram as informações veiculadas. O vídeo polêmico também serviu de alerta sobre a propagação de informações falsas e da desinformação nas mídias sociais.

Em 28 de fevereiro de 2020, o canal do YouTube de divulgação científica Nunca vi 1 cientista publicou o vídeo intitulado "Vídeo do álcool gel no WhatsApp é mentira", no qual a pesquisadora Laura de Freitas contesta as afirmações encontradas no vídeo do WhatsApp com base em argumentos 
científicos, esclarece dúvidas em relação à prevenção ao coronavírus e alerta sobre o compartilhamento de mensagens falsas nas mídias sociais. O vídeo com 7 minutos e 40 segundos de duração suscitou o engajamento do público e em 15 de março de 2020 contava com 43.703 visualizações, 3,7 mil likes, 77 dislikes e 467 comentários.

Dada a relevância social do tema, evidenciada pelo engajamento dos usuários, o presente estudo teve por objetivo caracterizar as práticas discursivas associadas ao "Vídeo do álcool gel no WhatsApp é mentira" e identificar expressões do comportamento informacional nos comentários dos usuários.

Os comentários em mídias sociais são pensados neste estudo como práticas discursivas ou atos verbais que podem revelar comportamentos, opiniões, crenças e atitudes dos indivíduos. A análise de conteúdo das práticas discursivas foi escolhida, dessa forma, como via de acesso ao comportamento informacional expresso nos comentários ao "Vídeo do álcool gel no WhatsApp é mentira". A partir dos resultados, busca-se compreender as relações estabelecidas entre o comportamento informacional dos usuários e o conteúdo publicado no vídeo.

\section{DESINFORMAÇÃO}

$\mathrm{Na}$ língua inglesa duas palavras são usadas para representar a desinformação: misinformation e disinformation. Ambas significam informações falsas, porém misinformation é compreendida como falsidade acidental, enquanto disinformation é interpretada como falsidade deliberada (STAHL, 2006). A palavra disinformation corresponde à disseminação de informações incompletas, imprecisas e enganosas com o propósito de enganar outras pessoas sobre a verdade e carrega um sentido de intencionalidade que não faz parte da acepção de misinformation (FETZER, 2004). Em outras palavras, a disinformation é compreendida como "[...] informação enganosa que tem a função de ludibriar alguém." (FALLIS, 2015, p. 413).

Para Karlova e Fisher (2013), misinformation pode ser entendida como 
informação imprecisa e disinformation como informação enganosa. A disinformation pode apresentar características semelhantes à misinformation e à informação, como a veracidade, a precisão, a integridade e a atualidade, porém é vista como uma informação propositalmente enganosa. A misinformation pode ser falsa e a disinformation verdadeira, mas ambas são consideradas subcategorias de informação e podem conter informatividade. As autoras também consideram misinforming e disinforming como formas de comportamento informacional que precisam ser exploradas no âmbito do letramento informacional.

Pinheiro e Brito (2014) identificaram três concepções principais para o termo desinformação na literatura científica nacional e internacional: a desinformação como uma ausência de cultura ou competência informacional; a desinformação como fornecimento de produtos informacionais de baixo nível cultural; e a desinformação como o ato de desinformar alguém propositalmente para enganá-lo. De acordo com os autores, a primeira definição foi encontrada na literatura científica brasileira, enquanto a última mostrou-se preponderante na literatura anglo-saxã.

As intenções para a disinformation podem ser benevolentes e motivadas socialmente, como mentir sobre uma festa surpresa, aderir a valores culturais e demonstrar pertencimento à comunidade, ou antagônicas e motivadas por interesses pessoais, como manipular o preço das ações do concorrente, controlar uma população e prejudicar a reputação de alguém. Contudo, a natureza e o grau das intenções envolvidas não podem ser determinados apenas pelo comportamento ou discurso. A crença do indivíduo não é uma condição indispensável para a difusão da informação, da misinformation e da disinformation e, mesmo que ele expresse sua crença, as intenções por trás dessa declaração não são transparentes (KARLOVA; FISHER, 2013).

A disinformation pode ser identificada tanto pelo conteúdo (ou linguagem) como pelos aspectos formais das mensagens. De acordo com Karlova e Fisher (2013), os enganadores podem usar sinais de credibilidade para enganar e os receptores podem usar sinais de engano para se defender. A eficácia do engano ou da defesa irá depender do grau de suspeita dos 
receptores em relação à misinformation ou disinformation ou da medida em que características das mensagens forem consideradas suspeitas, falsas ou benignas. As autoras mencionam como exemplo os e-mails de phishing ${ }^{1}$, que podem apresentar informações [duvidosas] com a indicação de origem no cabeçalho, erros de ortografia e gramática, além de hiperlinks externos que remetem a URLs falsas ou suspeitas.

A desinformação aparece frequentemente associada aos conceitos de pós-verdade e fake news. Pós-verdade é o termo usado para designar a era atual, na qual as pessoas mostram uma inclinação maior para acreditar em informações que apelam para emoções ou crenças existentes em detrimento da busca e da aceitação imediata de informações factuais e objetivas. A pósverdade é vista como uma das razões pelas quais as fake news (notícias falsas) se impuseram e se tornou mais difícil combater e interromper a produção e a propagação de informações intencionalmente falsas (COOKE, 2017).

Gelfert (2018) classifica as fake news como uma espécie de disinformation e as descreve como alegações falsas ou enganosas, apresentadas como notícias, que enganam o público-alvo deliberadamente, produzindo falsas crenças, e são enganosas por design. A especificidade das fake news consiste no fato de que a natureza enganosa das alegações é resultado de características sistêmicas relacionadas ao modo como conteúdo é escolhido e apresentado, isto é, à forma como o processo de geração e propagação das fake news é concebido.

Para Gray, Bounegru e Venturini (2017), as fakes news não podem ser compreendidas totalmente sem levar em conta sua circulação on-line. Os autores ressaltam que o caráter de circulação e recepção on-line é o que transforma algo em fakes news. As fakes news podem ser compreendidas, desse modo, não apenas em termos de conteúdo ou formato da mensagem, mas também com relação às infraestruturas mediadoras, plataformas digitais e culturas participativas que promovem a sua circulação.

\footnotetext{
${ }_{1}$ Práticas fraudulentas realizadas com o objetivo de obter dados pessoais na internet para fins escusos.
} 
O debate sobre a desinformação tornou-se primordial com a popularização crescente das mídias sociais, pois um volume expressivo de informações falsas é produzido e disseminado todos os dias por esses meios. Segundo Cooke (2017), as mídias sociais têm um papel relevante na sobrecarga de informações, pois permitem a disseminação de informações, falsas ou não, de maneira rápida. Além disso, as gratificações instantâneas relacionadas aos atos de compartilhar stories, ser o primeiro a curtir algo ou colecionar reações de amigos podem servir de estímulo à disseminação de notícias falsas.

Outra característica que tem favorecido a propagação da desinformação são os chamados "filtros-bolha" ou "câmaras de eco". Ambos os termos são usados para representar o resultado de uma cuidadosa curadoria de feeds de mídias sociais que mantêm os usuários cercados por pessoas com ideias afins e informações coerentes com suas crenças (COOKE, 2017). Os "filtros-bolha" contribuem para a desinformação na medida em que os usuários são expostos a informações que reforçam suas opiniões e visões de mundo, mesmo que essas informações possam estar incorretas, manipuladas ou fora de contexto. A ideia de filtros-bolha não abre espaço para o contraditório, o que seria desejável para um julgamento adequado da informação.

A desinformação nas mídias sociais também é influenciada pela exposição seletiva e pela satisfação. A ideia de exposição seletiva, abordada na seção seguinte, parte do pressuposto de que os usuários tendem a evitar informações consideradas desagradáveis ou perturbadoras em seus filtrosbolha (COOKE, 2017). Já a satisfação consiste na reunião de dados, opiniões e impressões boas o suficiente para que os usuários se sintam satisfeitos com o processo de busca, mesmo que não tenham feito todas as tentativas possíveis para a obtenção de informações mais completas, precisas e detalhadas (CASE, 2007). Ao permitir a circulação de informações de baixa qualidade, a satisfação contribui para promover a misinformation, a disinformation e as fake news. Embora a informação não seja a melhor, é considerada suficientemente boa para não ser colocada à prova (COOKE, 2017). 
Tendo em vista a influência do modo como as pessoas lidam com a informação na disseminação da desinformação em suas diferentes formas, a próxima seção abordará um conceito importante para compreender esse fenômeno: o comportamento informacional.

\section{COMPORTAMENTO INFORMACIONAL, ATITUDES E OPINIÕES}

Comportamento informacional é a subárea da Ciência da Informação que abrange estudos realizados com o objetivo de compreender a relação dos seres humanos com a informação. $O$ termo também é usado para designar as múltiplas formas pelas quais as pessoas interagem com a informação e, mais precisamente, o modo como os indivíduos buscam e usam a informação (BATES, 2010). Para Cooke (2017), os comportamentos de busca, seleção, evitação e uso da informação ajudam a compreender como as informações são consumidas diariamente e a explicar a suscetibilidade dos indivíduos às fake news.

O comportamento de busca da informação (information seeking behavior) é definido como $\mathrm{o}$ ato de buscar informações intencionalmente em decorrência da necessidade de se atingir um objetivo. Já o comportamento de uso da informação (information use behavior) corresponde aos atos físicos e mentais implicados na assimilação da informação aos conhecimentos prévios do indivíduo (WILSON, 2000). A seleção e a evitação podem ser compreendidas como ações empreendidas pelo usuário ao se deparar com a informação. A seleção da informação é o comportamento real, apoiado em julgamentos e decisões tomadas internamente, que pode ser diretamente observado (RIEH, 2002). A evitação é entendida, por sua vez, como uma tendência à rejeição de informações conflitantes com conhecimentos, crenças e atitudes ou que gerem ansiedade (CASE, 2007). Outro conceito relevante para a compreensão do comportamento informacional nas mídias sociais é o compartilhamento da informação, que ocorre quando informações são disponibilizadas pelos indivíduos de maneira voluntária (DAVENPORT; PRUSAK, 1998). 
Desde o início dos anos oitenta diferentes modelos teóricos têm sido propostos para explicar como os indivíduos se relacionam com a informação desde a constatação de uma necessidade de informação, passando pelo processo de busca da informação, até o efetivo uso da informação. Os modelos demonstram que existem diversas variáveis ou fatores intervenientes no comportamento informacional, porém pouca atenção é dada ao fato de que os usuários se posicionam frente à informação com que entram em contato. Esse posicionamento vai além da avaliação da qualidade da informação por meio de critérios objetivos (utilidade, confiabilidade, precisão, etc.). As pessoas formam opiniões sobre as informações que circulam em diferentes contextos e a propagação de informações duvidosas no ambiente digital alerta para a importância de se compreender tal comportamento.

Em seu modelo de comportamento informacional revisado, Wilson (1997) situa a exposição seletiva como uma das barreiras que podem intervir no comportamento de busca da informação. O conceito é definido por Rogers (1983) como uma tendência de exposição a ideias que estão de acordo com os interesses, necessidades, atitudes ou crenças dos indivíduos. Segundo o autor, as predisposições influenciam o comportamento dos indivíduos em relação às mensagens recebidas e seus efeitos potenciais. Já as mensagens em conflito com as predisposições individuais são, consciente ou inconscientemente, evitadas.

Para Wilson (1997), a exposição seletiva também estaria presente no processamento da informação e na aprendizagem. $O$ autor considera provável que os mesmos processos seletivos estejam em jogo no exame de informações para determinar seu valor. A apropriação da noção de exposição seletiva em seu texto, mesmo que de forma incidental, é um indicativo de que os fatores pessoais que interferem na busca e no uso da informação merecem a atenção nas pesquisas sobre o comportamento informacional.

Para compreender o que se poderia denominar de atitude em relação à informação torna-se necessário ultrapassar os limites do campo da Ciência da Informação e buscar subsídios em outras áreas das ciências humanas e sociais. 
A noção de atitude pode ser compreendida como um estágio anterior ao comportamento ou uma predisposição do indivíduo para agir de uma determinada forma. É importante sublinhar que a atitude e o comportamento podem não ser congruentes, tendo em vista que a conduta do indivíduo é, muitas vezes, contrária à atitude (RUÓTOLO, 1998). A atitude também pode ser considerada o condutor do comportamento manifesto pelo receptor ou $\mathrm{O}$ indicador de que o indivíduo está interiormente disposto à ação. Se a atitude é uma predisposição não manifesta do comportamento, a opinião pode ser vista como a expressão dessa predisposição (FERREIRA, 2014).

A palavra opinião (do latim opinio, -onis) significa modo de ver pessoal; juízo que se forma de alguém ou alguma coisa; adesão pessoal ao que se crê como bom e verdadeiro; manifestação de ideias individuais a respeito de algo ou alguém; credo político; sentimento exagerado de orgulho ou confiança em si próprio (OPINIÃO, c2020). Na obra de Platão, o termo doxa é compreendido como simples opinião ou juízo subjetivo que possui valor apenas momentâneo e abrange uma noção de julgamento e sentimento, no sentido de resolução e decisão parcial, baseada exclusivamente nos dados presentes (FRANKLIN, 2004). Os pensadores gregos, como Platão, consideravam a noção de doxa (opinião) como oposta ao conhecimento epistêmico (verdadeiro) por expressar particularidades ligadas às percepções (que podem ser errôneas) ou a passionalidade dos indivíduos (SILVA, 2016).

Viana (2015) divide as opiniões em momentâneas, simuladas e resistentes. As opiniões momentâneas emergem em um dado momento e podem ser rapidamente substituídas. Ocorrem, por exemplo, quando um indivíduo toma uma posição sobre uma determinada questão a partir de um conjunto restrito de informações e muda sua opinião ao se defrontar com outra pessoa com opinião contrária, porém mais informada e com mais argumentos. As opiniões simuladas, por sua vez, surgem em contextos em que há forte pressão e repressão, efervescência social ou mesmo interesses e oportunismo. É o caso, por exemplo, do indivíduo que acaba sendo coagido a votar a favor de algo que não concorda intimamente ao ser realizada uma votação sobre algo que parece consensual em uma instituição. As opiniões resistentes são 
também infundadas, mas sua maleabilidade é menor. Manifestam-se devido à força da hegemonia ou da cultura sobre os indivíduos ou, particularmente, em casos de pessoas que não admitem errar e mantém uma opinião sem apresentar argumentos e se convencer de sua veracidade.

De acordo com Kelman (1961), o "significado" das posições adotadas pelos indivíduos e segmentos da população é a uma preocupação constante na análise dos dados de opinião pública. Para compreender o que os dados de opinião significam, é preciso ir além da análise das respostas de um indivíduo ou da distribuição das respostas na população e buscar informações sobre as características das opiniões observadas (intensidade, relevância, nível de comprometimento), as bases motivacionais dessas opiniões (funções para os indivíduos e sistemas motivacionais subjacentes) e os vínculos cognitivos das opiniões (quantidade e natureza das informações basilares, avaliações específicas e expectativas relacionadas).

Kelman (1961) classificou os processos de influência social sobre a formação e a mudança de opinião em três tipos. A conformidade pode ser observada quando um indivíduo aceita a influência de uma pessoa ou grupo com a expectativa de alcançar uma reação favorável, obter determinadas recompensas ou evitar punições controladas pelo agente influenciador. $O$ indivíduo não adota uma opinião específica porque acredita em seu conteúdo, mas porque é uma condição necessária para se obter um efeito social satisfatório.

A influência social por meio da identificação ocorre quando o indivíduo constitui uma relação de identidade ou reciprocidade com o intuito de estabelecer ou manter um relacionamento desejado com o outro ao mesmo tempo em que contribui para sua autoimagem. As opiniões adotadas através da identificação estão vinculadas a fontes externas, dependem do apoio social e não são incorporadas aos valores do indivíduo. Por fim, a internalização se dá quando a influência social é aceita porque o comportamento induzido está de acordo o sistema de valores do indivíduo, o que não quer dizer que ele expresse opiniões internalizadas independentemente da situação social (KELMAN, 1961). 
Pelo exposto, pode-se depreender que as expectativas dos indivíduos em relação a si próprios e aos outros são elementos fundamentais na formação de opiniões em um dado contexto. A influência social não é apenas um imperativo externo. Fatores internos são necessários para que se produzam resultados efetivos sobre o comportamento, as atitudes e as opiniões dos indivíduos e esses fatores podem determinar o caráter das opiniões. As opiniões podem, ainda, se apresentar de diferentes formas de acordo com sua relevância para os indivíduos. A análise da opinião deve levar em conta não apenas a influência dos meios de comunicação (conteúdo), mas também os aspectos individuais e sociais intervenientes na manifestação do julgamento.

A compreensão sobre a natureza das opiniões e o modo como são formadas é particularmente relevante no estudo da informação e da desinformação nas mídias sociais, pois permite entender os aspectos sociais e individuais que de alguma forma concorrem para a atitude dos indivíduos em relação à informação.

\section{PROCEDIMENTOS METODOLÓGICOS}

O presente estudo trata-se de uma pesquisa de natureza básica, nível exploratório e abordagem qualitativa. A análise de conteúdo foi escolhida como método de pesquisa devido às características do material empírico e o foco sobre os significados emergentes. As técnicas da análise de conteúdo foram aplicadas a fim de ampliar o conhecimento sobre as reações dos usuários das mídias sociais em relação ao tema desinformação expressas nos comentários ao "Vídeo do álcool gel no WhatsApp é mentira" do canal de divulgação científica do YouTube Nunca vi 1 cientista.

O corpus do estudo foi formado pelo vídeo sobre a eficácia do álcool gel, que circulou no final de fevereiro de 2020 no aplicativo WhatsApp, pelo "Vídeo do álcool gel no WhatsApp é mentira", publicado em 28 de fevereiro de 2020 pelo canal Nunca vi 1 cientista, e pelos comentários ao segundo vídeo no YouTube. Os vídeos foram usados para a contextualização dos dados, pois o foco principal da análise foram as práticas discursivas emergentes a partir dos 
comentários. Os comentários ao "Vídeo do álcool gel no WhatsApp é mentira" foram coletados em 15 de março de 2020 com o auxílio do software NVivo. Entre os 467 comentários disponíveis no momento da coleta, 252 eram comentários ao vídeo e 215 respostas aos comentários.

A análise de conteúdo foi conduzida de acordo com as etapas de preparação, unitarização, categorização, descrição e interpretação (MORAES, 1999). A etapa de preparação das informações foi realizada durante a organização dos dados, quando as respostas aos comentários foram separadas do corpus por representarem interações de outra ordem e exigirem uma abordagem distinta. Assim, o recorte empírico definitivo foi constituído pelos 252 comentários ao vídeo. Os comentários foram codificados com o código numérico ID da linha fornecido pelo software NVivo na importação dos dados.

A etapa de unitarização inclui a definição das unidades de análise, a identificação dessas unidades de análise, o seu isolamento e a definição das unidades de contexto. As unidades de análise são os elementos unitários de conteúdo que serão submetidos à categorização (MORAES, 1999). Já as unidades de contexto são superiores às unidades de análise e permitem a compreensão dos significados dos itens examinados quando há ambiguidade (BARDIN, 1977). A unidade de análise escolhida no estudo foi a frase por representar um enunciado com sentido completo e permitir a distinção entre as práticas discursivas expressas nos comentários dos usuários. Os vídeos e comentários completos foram considerados as unidades de contexto, servindo de referência para eliminar possíveis dúvidas em relação ao sentido das unidades de análise. A identificação e 0 isolamento das unidades de análise (fragmentação) foram realizados concomitantemente durante a leitura dos comentários na etapa de categorização.

A categorização é o agrupamento ou classificação dos dados de acordo com suas semelhanças ou características em comum (MORAES, 1999). O principal critério usado neste estudo para a classificação das frases foi 0 conceito de práticas discursivas, compreendidas como "[...] speech acts ou atos de fala, expressão cunhada pela etnometodologia para se referir à orientação 
do uso da linguagem para a ação." (SPINK; MEDRADO, 2000, p. 47). Nesse sentido, a mensagem "Muito obrigada pela informação!" (ID 106) pode ser vista como um ato de agradecimento realizado por meio da fala.

No processo de categorização foi realizada a leitura e a análise indutiva dos dados de modo a permitir a identificação das práticas discursivas expressas nos comentários. As categorias emergiram no decorrer da análise e receberam uma definição que foi aprimorada ao longo do processo. Os dados foram submetidos a revisões constantes a fim de assegurar uma classificação mais precisa. As categorias também foram revisadas diversas vezes para garantir sua homogeneidade. Os rótulos atribuídos às categorias foram revisados durante o processo de análise para se ajustarem ao conteúdo das mensagens. Quando necessário, as unidade de contexto foram consultadas para dirimir as dúvidas sobre a classificação dos dados. Cabe destacar que cada unidade de análise foi classificada em apenas uma categoria, atendendo ao critério de exclusividade ou exclusão mútua (MORAES, 1999).

Ao término da categorização, os 252 comentários ao vídeo foram divididos em 354 unidades de análise. Já as unidades de análise foram distribuídas entre as dez categorias emergentes. Uma das categorias reuniu o maior número de mensagens e foi subdividida em sete subcategorias. A caracterização das práticas discursivas contribuiu para identificar expressões do comportamento informacional nos comentários ao "Vídeo do álcool gel no WhatsApp é mentira", enquanto o estabelecimento das subcategorias foi relevante por demonstrar como os usuários formularam suas opiniões.

\section{RESULTADOS E DISCUSSÃO}

Um dos objetivos do estudo foi caracterizar as práticas discursivas associadas ao "Vídeo do álcool gel no WhatsApp é mentira". As práticas discursivas podem ser compreendidas como atos verbais ou ações realizadas através da fala. $O$ conceito é particularmente relevante para o estudo do comportamento informacional em mídias sociais na medida em que os comentários dos usuários tendem a revelar como eles reagem ou se 
posicionam frente ao conteúdo com o qual entram em contato. O próprio ato de fazer um comentário sobre uma postagem pode ser visto como uma reação, assim como as ações de visualizar, curtir e compartilhar informações. Esses e outros aspectos são indicadores do chamado engajamento com o conteúdo.

$\mathrm{Na}$ análise do corpus, foram identificadas dez práticas discursivas relacionadas ao "Vídeo do álcool gel no WhatsApp é mentira", representadas pelas categorias opinar, ironizar, relatar, felicitar, agradecer, perguntar, engajar, contribuir, apoiar e solicitar. A prática discursiva predominante foi opinar, perfazendo $50 \%$ das unidades de análise (Gráfico 1). A expressividade da categoria pode ser considerada uma evidência de que a formação de opinião ou o julgamento sobre o conteúdo publicado é um aspecto relevante para os usuários. Os indivíduos não apenas consomem o conteúdo como também usam o meio que têm à disposição para se manifestar sobre ele. Essa constatação contrapõe-se à ideia do usuário como um sujeito passivo diante da informação, conforme postulavam os estudos de necessidades e usos da informação tradicionais (DERVIN; NILAN, 1986).

\section{Gráfico 1 - Práticas discursivas nos comentários ao "Vídeo do álcool gel no WhatsApp é mentira".}

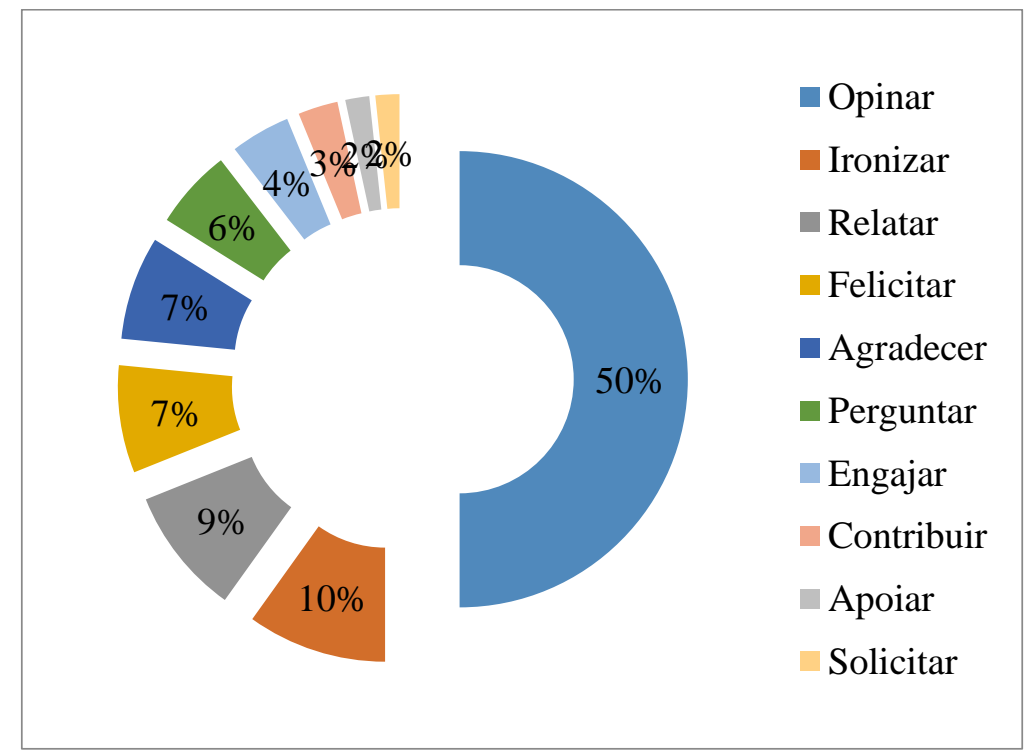

Fonte: Dados da pesquisa.

A categoria opinar foi formada por 177 mensagens que correspondem a $50 \%$ das unidades de análise. As mensagens incluídas nesta categoria 
expressam o posicionamento ou julgamento dos usuários acerca dos temas abordados no "Vídeo do álcool gel no WhatsApp é mentira" ou sobre a produção do vídeo em si. Pode-se considerar que o teor das opiniões foi positivo em $70 \%$ dos casos. Cerca de $30 \%$ das mensagens continham conteúdo desfavorável ou pessimista. Devido à heterogeneidade das opiniões identificadas, as mensagens foram distribuídas em sete subcategorias (Gráfico 2).

\section{Gráfico 2 - Opiniões sobre o "Vídeo do álcool gel no WhatsApp é mentira".}

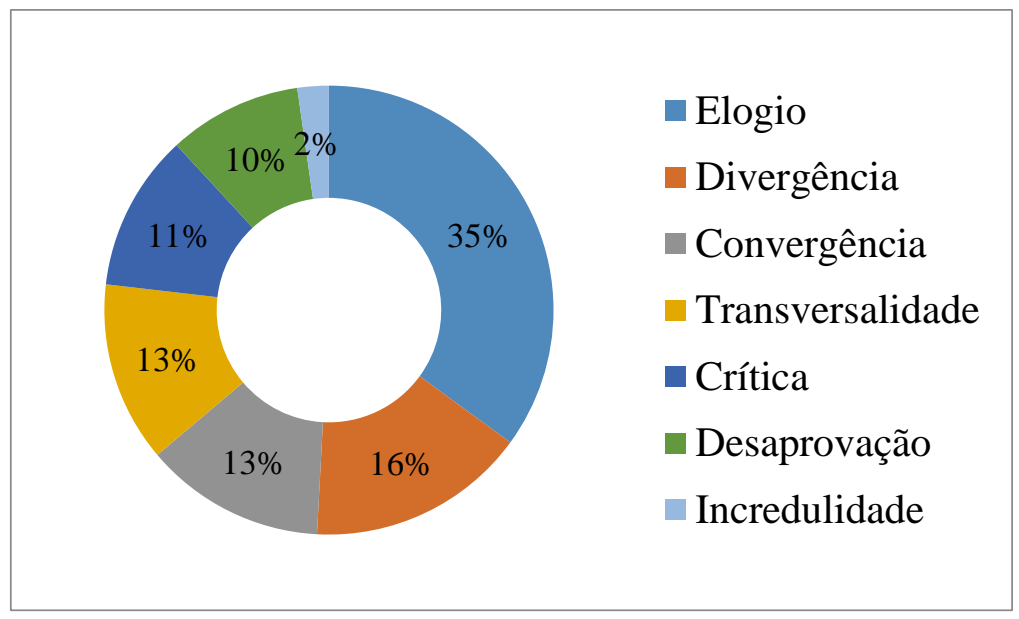

Fonte: Dados da pesquisa.

A subcategoria elogio foi a mais expressiva entre as subcategorias de opinar e entre as práticas discursivas de modo geral, representando $35 \%$ das mensagens de opinião e $17,5 \%$ das unidades de análise no total. As 62 mensagens incluídas nesta subcategoria consistem em elogios ao vídeo e ao canal, destacando o caráter esclarecedor do conteúdo e a relevância do trabalho desenvolvido. Mensagens como "Finalmente um vídeo confiável." (ID 1), "Excelente explicação!" (ID 80), "Nossa, que canal super didático. Que bom que conheci!" (ID 141) e "Que utilidade pública!" (ID 246) demonstram que a confiabilidade das informações, a linguagem compreensível e a relevância do conteúdo são aspectos levados em conta na avaliação dos usuários.

A segunda subcategoria de opinião com maior número de mensagens foi divergência. As 28 mensagens que compõem esta categoria possuem em comum o fato de discordarem ou questionarem as informações apresentadas no "Vídeo do álcool gel no WhatsApp é mentira". Algumas mensagens refletem 
um posicionamento condizente com as alegações do "químico autodidata", outras contestam as afirmações realizadas no vídeo do YouTube e até mesmo a autoridade acadêmica. A mensagem ID 267 é um exemplo de que a seleção de informações e fontes de informação é influenciada por crenças, atitudes e conhecimentos prévios (WILSON, 1997): "Olha o vinagre é uma excelência meus avós me ensinavam e uso até hoje. Prefiro vinagre quê é milinar.".

Na mensagem ID 335, o usuário questiona uma passagem do vídeo na qual a autora explica que a máscara seria indicada para pessoas doentes a fim de evitar a transmissão do vírus para outras pessoas: "O que mais me deixou na dúvida neste vídeo foi quando a médica falou que não adiantava nada usar máscara. Ora, se isto for verdade, porque vemos (nas fotos dos jornais) as autoridades e profissionais da área de saúde (todos) usando máscaras?!?!?". É importante ressaltar que, no Brasil, o uso da máscara pela população em geral não fazia parte do protocolo inicial de prevenção à Covid-19 e foi incorporado posteriormente (NOVO..., 2020). Dessa forma, a informação estava de acordo com as recomendações das autoridades de saúde vigentes à época da publicação do vídeo. A mensagem ID 335 também revela que, mesmo quando se trata de conteúdo presumivelmente confiável, os usuários estão atentos a enganos que podem ocorrer.

A subcategoria convergência foi composta por 23 mensagens nas quais os usuários expressam opiniões condizentes com o conteúdo do "Vídeo do álcool gel no WhatsApp é mentira" ou compreendidas como tal. As mensagens "Sarampo, dengue! Vamos falar sobre isso tb" (ID 145), "Concordo plenamente!!" (ID 203) e "Pior é que tem gente que ainda hoje continua acreditando e defendendo o químico de vinagre, quer dizer, de araque." (ID 225) são exemplos que expressam posicionamentos em consonância com o vídeo do canal Nunca vi 1 cientista.

Já a subcategoria transversalidade também conta com 23 mensagens e merece destaque por reunir opiniões dos usuários sobre temas que atravessam o conteúdo do vídeo, como o compartilhamento de informações falsas, a suscetibilidade das pessoas às fake news, o anticientificismo e a pseudociência. Na mensagem ID 182, observa-se uma percepção sobre a 
propagação de informações falsas nas mídias sociais e suas consequências: "Infelizmente essas fake news esse [sic] espalham mais rápido que 0 esclarecimento da mentira. E o pior é que a quantidade de gente que vai acreditar e parar de usar álcool vai ser grande. Além de ter compartilhado e adotado a prática sem se certificar da veracidade.". As mensagens incluídas na subcategoria demonstram que o vídeo serviu de estímulo à reflexão sobre o caráter nocivo da desinformação na sociedade.

A subcategoria crítica foi formada por 20 mensagens nas quais os usuários avaliam aspectos relativos à produção do "Vídeo do álcool gel no WhatsApp é mentira", como o volume do áudio e a velocidade da fala da autora. A subcategoria desaprovação, por sua vez, inclui 18 mensagens que expressam reprovação ao vídeo do WhatsApp e, particularmente, ao comportamento do autor: "Um desrespeito esse cidadão auto didata" (ID 115). Um aspecto relevante, levantado por um usuário, é a questão da intencionalidade do vídeo: "Este video é horrível mesmo .Desconfio que seja até falso pra descredibilizar todo mundo que faça video na internet." (ID 210). Como já foi apontado por diversos autores, um elemento definidor da desinformação enquanto prática é a intenção subjacente à difusão de informações falsas. Ao mesmo tempo em que contribui para qualificar um determinado conteúdo como desinformação, a intencionalidade pode ser considerada uma das características mais difíceis de aferir tendo em vista que a intenção para a desinformação nem sempre está explícita e a prática pode ser realizada com múltiplos propósitos.

A incredulidade é a última subcategoria de opinião, contendo o menor número de mensagens. Os quatro comentários incluídos na subcategoria denotam ceticismo em relação ao conteúdo de ambos os vídeos. Na mensagem ID 435, o usuário questiona a credibilidade da formação acadêmica: "Todos falam a mesma coisa . que são doutorados formados nada [sic] melhores faculdades Etc mas não mostram seus registros e diplomas . resumindo . não acredito em ninguém." A percepção do usuário pode ser interpretada como um dos efeitos da desinformação: a perda da confiança no discurso acadêmicocientífico. Para Bruno e Roque (2019, p. 17), "a confiança está sendo minada 
nas redes sociais, com novas crenças e novos valores que contestam o método científico e desafiam consensos há tempos estabelecidos".

Ironizar é a segunda maior categoria com 35 mensagens. Grande parte delas satiriza a declaração do autor do vídeo do WhatsApp de que seria "químico autodidata", como pode ser visto na mensagem ID 66: "Filósofo auto declarado. No curriculo: Harvard 'pq tenho intenção de um dia estudar lá'. E agora: químico auto didata. Eh... estamos cada vez melhor, Br!". A categoria também inclui mensagens de humor sobre o uso do álcool em gel e outros produtos na prevenção ao coronavírus. A prática do humor também foi mencionada no estudo de Corrêa e Vanz (2020) sobre a formação do capital social no YouTube. Os autores identificaram comentários nos quais os usuários buscavam provocar o riso ou demonstravam terem achado algo engraçado. Porém, grande parte das mensagens incluídas na categoria ironizar sugerem que a ironia foi usada para desacreditar o autor do vídeo do WhatsApp por se apresentar como especialista em uma área sem a respectiva formação, o que demonstra que o humor também pode ser empregado como instrumento de crítica pelos usuários nas mídias sociais.

A categoria relatar configura-se como uma das mais heterogêneas no que tange aos assuntos abordados e inclui 32 mensagens nas quais os usuários relatam o recebimento de informações falsas ou duvidosas, explicam como normalmente reagem a essas informações, descrevem suas reações ao vídeo do WhatsApp, revelam como chegaram ao "Vídeo do álcool gel no WhatsApp é mentira" e mencionam fatos relacionados ao álcool em gel, à pandemia do coronavírus e ao uso do vinagre. As mensagens "Quando ele fala que é químico autodidata acabou a credibilidade...." (ID 360) e "Eu recebi esse vídeo, mas não repassei, não sabia se era verdade ou não. Mas parei de usar o álcool kkk" (ID 412) são exemplos de relatos apresentados.

A categoria felicitar abrange 27 mensagens nas quais os usuários parabenizam o canal Nunca vi 1 cientista pelo vídeo publicado e pelo trabalho de divulgação científica. Tal prática é ilustrada na mensagem ID 16: "Parabéns por divulgar ciência, Laura!". A categoria agradecer está diretamente relacionada com a anterior e inclui 26 mensagens em que os usuários 
expressam gratidão pelo vídeo e pelo trabalho realizado pelo canal. A mensagem "Muito obrigada pela informação!" (ID 106) é um exemplo. Em ambas as categorias são perceptíveis a valorização do conteúdo publicado e a avaliação positiva dos usuários.

As 20 mensagens com perguntas em relação ao conteúdo do vídeo compõem a categoria perguntar. As questões se referem, predominantemente, ao produto álcool em gel, mas também foram identificadas dúvidas sobre aspectos relacionados indiretamente ao "Vídeo do álcool gel no WhatsApp é mentira". As mensagens incluídas na categoria mostram que os comentários são usados para sanar dúvidas sobre aspectos que não foram tratados no vídeo. Na mensagem ID 439 são apresentadas algumas questões sobre o tema do vídeo: "PERGUNTA: 1- O álcool gel é feito de que tipo de álcool? 2Álcool isopropílico é eficiente para combater: germes, bactéria e vírus?". Um comportamento semelhante foi observado no estudo de Marcusso (2013) sobre as manifestações dos usuários em relação a filmes publicitários que apresentaram elementos dissonantes e alcançaram grande repercussão no YouTube. Para o autor, a categoria "perguntando uma questão" foi constituída por dúvidas relacionadas direta ou indiretamente com as três peças analisadas, representando 3,04 \%, 3,44 \% e 3,92 \% dos comentários de cada vídeo.

$\mathrm{Na}$ categoria engajar é possível observar como o conteúdo mobilizou o comportamento dos usuários. A categoria é constituída por 15 mensagens nas quais os usuários revelam que compartilharam o vídeo com outras pessoas ou se inscreveram no canal. As mensagens "Compartilhei em vários grupos pedindo que repliquem" (ID 86) e "Ganhou um inscrito." (ID 332) são manifestações do engajamento com o vídeo, explicitado pelos comentários.

A categoria contribuir inclui 10 mensagens visando colaborar com conteúdo adicional sobre o tema abordado vídeo. Os usuários compartilham informações sobre a eficácia de produtos na desinfecção, explicações sobre a utilização de substâncias mencionadas no "Vídeo do álcool gel no WhatsApp é mentira", notícias sobre a repercussão do vídeo do WhatsApp, bem como links de vídeos no YouTube, relacionados ou não com a temática. A mensagem ID 242 é um exemplo de informação compartilhada: "Os dentistas utilizam 
hipoclorito de sódio para matar vírus e bactérias".

A categoria apoiar é formada por seis mensagens de incentivo ao canal. Embora outras categorias possam representar formas de apoio ao trabalho desenvolvido, esta categoria reúne mensagens que expressam a ideia de maneira direta, como na seguinte mensagem: "Juntos combatendo fake news!!!" (ID 158). No estudo realizado por Corrêa e Vanz (2020), as mensagens de apoio apresentavam conteúdo afetivo importante, expressando solidariedade e preocupação para com os usuários que declaravam conviver com o problema da depressão. O que a categoria apoiar e a subcategoria mensagens de apoio possuem em comum é o fato de se caracterizarem com formas de suporte social. No primeiro caso as mensagens são dirigidas ao canal, enquanto no segundo caso as mensagens têm como destinatários outros usuários que comentaram o vídeo. $\mathrm{O}$ apoio recebido dos usuários é mencionado por criadores de conteúdo para o YouTube como uma de suas motivações para a produção de vídeos.

A última prática discursiva identificada no corpus é representada pela categoria solicitar. As mensagens incluídas na categoria correspondem, em sua maioria, a pedidos para que o canal aborde temas relacionados ao conteúdo do vídeo. É o caso, por exemplo, da mensagem ID 458: "Será que vc pode fazer um vídeo sobre álcool em gel 'caseiro' ? Tá rolando uns vídeos tipo

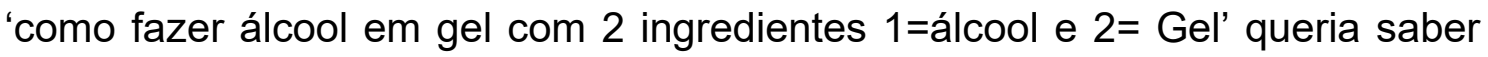
se funciona mesmo mas queria uma opinião de um(a) cientista" (ID 458). A mensagem permite depreender que a autoridade do canal no esclarecimento de informações falsas ou enganosas é reconhecida pelos usuários.

As categorias relatar, perguntar, engajar, contribuir e solicitar, bem como as subcategorias elogio, convergência e crítica apresentaram expressões compatíveis como os comportamentos de busca, compartilhamento, avaliação e uso da informação. As categorias perguntar e solicitar revelam que os usuários reconhecem no canal um espaço para a busca de informações científicas e utilitárias. Já as categorias engajar e contribuir representam duas formas de compartilhamento da informação: o conteúdo do vídeo e o conhecimento pessoal. Na categoria relatar foi possível constatar que alguns 
usuários posicionaram-se criticamente em relação ao vídeo do WhatsApp suspeitando do conteúdo e das credenciais do autor, ou seja, realizando a avaliação da informação. As subcategorias elogio e crítica também estão diretamente relacionadas à avaliação da informação, julgando sua qualidade e aspectos relativos à transmissão do conteúdo. Por fim, o uso do conteúdo do "Vídeo do álcool gel no WhatsApp é mentira" foi mencionado de forma pontual na categoria relatar e indiretamente na subcategoria convergência.

\section{CONSIDERAÇÕES FINAIS}

O presente estudo teve por objetivo caracterizar as práticas discursivas relacionadas ao "Vídeo do álcool gel no WhatsApp é mentira" e identificar expressões do comportamento informacional nos comentários ao vídeo. Ao final da pesquisa foram identificadas dez práticas discursivas representadas pelas categorias opinar, ironizar, relatar, felicitar, agradecer, perguntar, engajar, contribuir, apoiar e solicitar. A categoria opinar, formada pelas subcategorias elogio, divergência, convergência, transversalidade, crítica, desaprovação e incredulidade, merece destaque por abranger $50 \%$ das unidades de análise. Sua expressividade comprova que os usuários não são receptores passivos, também manifestam seus posicionamentos em relação ao conteúdo que consomem.

As formas de comportamento informacional encontradas no estudo foram a busca, o compartilhamento, a avaliação e o uso da informação. A busca de informação foi observada nas categorias perguntar e solicitar; o compartilhamento nas categorias engajar e contribuir; a avaliação na categoria relatar e nas subcategorias elogio e crítica; e o uso da informação na categoria relatar e na subcategoria convergência. Pode-se considerar que, em conjunto, as mensagens correspondentes ao comportamento informacional foram bastante expressivas no corpus, o que demonstra que os usuários interagem com as informações veiculadas de diferentes formas.

Por fim, a caracterização das práticas discursivas expressas nos comentários mostrou-se um recurso útil para a identificação do comportamento informacional em relação ao vídeo e para ampliar o conhecimento sobre as 
formas de engajamento dos usuários com o conteúdo publicado no YouTube.

\section{REFERÊNCIAS}

BARDIN, Laurence. Análise de conteúdo. Lisboa: Edições 70, c1977.

BATES, Marcia J. Information behavior. In: McDonald, John D.; Levine-Clark, Michael (ed.). Encyclopedia of Library and Information Sciences. 4th ed. Boca Raton: CRC Press, c2017. p. 2074-2085.

BRUNO, Fernanda; ROQUE, Tatiana. A ponta de um iceberg de desconfiança. In: BARBOSA, Mariana (org.). Pós-verdade e fake news: reflexões sobre a guerra de narrativas. Rio de Janeiro: Cobogó, 2019. p. 13-23.

CASE, Donald O. Looking for information: a survey of research on information seeking, needs, and behavior. 2nd ed. London: Academic Press, 2007.

COOKE, Nicole A. Posttruth, truthiness, and alternative facts: information behavior and critical information consumption for a new age. The Library Quarterly, Chicago, v. 87, n. 3, p. 211-221, July 2017. Disponível em: https://doi.org/10.1086/692298. Acesso em: 14 maio 2020.

CORRÊA, Maurício de Vargas; VANZ, Samile Andréa de Souza. A formação do capital social no YouTube: estudo com base em um canal de divulgação científica de questões abordadas pela psicologia. Reciis: Revista Eletrônica de Comunicação, Informação e Inovação em Saúde, Rio de Janeiro, v. 14, n. 1, p. 167-183, jan./mar. 2020. Disponível em:

https://doi.org/10.29397/reciis.v14i1.1756. Acesso em: 28 jun. 2020.

DAVENPORT, Thomas H.; PRUSAK, Laurence. Cultura e comportamento em relação à informação. In: DAVENPORT, Thomas $\mathrm{H}$. Ecologia da informação: por que só a tecnologia não basta para o sucesso na era da informação. São Paulo: Futura, 1998. cap. 6.

DERVIN, Brenda; NILAN, Michael. Information needs and uses. Annual Review of Information Science and Technology, White Plains, v. 21, p. 3-33, 1986.

EUROPEAN CENTRE FOR DISEASE PREVENTION AND CONTROL. COVID19. Solna: ECDC, c2020. Disponível em: https://www.ecdc.europa.eu/en/novelcoronavirus-china. Acesso em: 23 mar. 2020.

FALLIS, Don. What is disinformation?. Library Trends, Urbana, v. 63, n. 3, p. 401-426, 2015. Disponível em: https://muse.jhu.edu/article/579342/pdf. Acesso em: 5 maio 2020.

FERREIRA, Raquel Marques Carriço. Os efeitos dos meios sobre as atitudes e comportamentos da audiência. Matrizes, São Paulo, v. 8, n. 1, p. 255-269, jan./jun. 2014. Disponível em: https://doi.org/10.11606/issn.19828160.v8i1p255-269. Acesso em: 23 abr. 2020. 
FETZER, James H. Information: does it have to be true? Minds and Machines, Dordrecht, v. 14, n. 2, p. 223-229, May 2004. Disponível em:

https://doi.org/10.1023/B:MIND.0000021682.61365.56. Acesso em: 6 maio 2020.

FRANKLIN, Karen. Os conceitos de doxa e episteme como determinação ética em Platão. Educar em Revista, Curitiba, n. 23, p. 374-374, jan./jun. 2004. Disponível em: http://ref.scielo.org/vpz73d. Acesso em: 26 abr. 2020.

GELFERT, Axel. Fake news: a definition. Informal Logic, Montréal, v. 38, n. 1, p. 84-117, 2018. Disponível em: https://doi.org/10.22329/il.v38i1.5068. Acesso em: 5 maio 2020.

GRAY, Jonathan; BOUNEGRU, Liliana; VENTURINI, Tommaso. Introduction. In: BOUNEGRU, Liliana et al. (comp.). A field guide to "fake news" and other information disorders: a collection of recipes for those who love to cook with digital methods. Amsterdam: Public Data Lab, c2017. p. 6-13.

KARLOVA, Natascha A.; FISHER, Karen E. A social diffusion model of misinformation and disinformation for understanding human information behaviour. Information Research, v. 18, n. 1, Mar. 2013. Disponível em: http://informationr.net/ir/18-1/paper573.html. Acesso em: 7 maio 2020.

KELMAN, Herbert C. Processes of opinion change. Public Opinion Quarterly, New York , v. 25, n. 1, p. 57-78, 1961. Disponível em: https://www.jstor.org/stable/2746461. Acesso em: 25 abr. 2020.

\section{MARCUSSO, Anderson. Comentários e dissonâncias em filmes}

publicitários no YouTube. 2013. Dissertação (Mestrado em Comunicação) Programa de Pós-Graduação em Comunicação, Universidade Municipal de São Caetano do Sul, São Caetano do Sul, 2013.

MORAES, Roque. Análise de conteúdo. Revista Educação, Porto Alegre, v. 22, n. 37, p. 7-32, 1999.

NOVO protocolo vai indicar máscara para quem não tem sintoma. 1 abr. 2020. Disponível em: https://www.terra.com.br/noticias/coronavirus/novo-protocolovai-indicar-mascara-para-quem-nao-temsintoma,562bad483811173c12f454ae3ccd255d33xvfrv4.html. Acesso em: 27 jun. 2020.

OPINIÃO. In: DICIONÁRIO Priberam da língua portuguesa. [Lisboa]: Priberam Informática, c2020. Disponível em: https://dicionario.priberam.org/opinião. Acesso em: 26 abr. 2020.

PINHEIRO, Marta Macedo Kerr; BRITO, Vladimir de Paula. Em busca do significado da desinformação. DataGramaZero, Rio de Janeiro, v. 15 n. 6, dez. 2014. Disponível em:

https://www.brapci.inf.br/index.php/article/view/0000016135. Acesso em: 5 maio 2020.

RIEH, Soo Young. Judgment of information quality and cognitive authority in the Web. Journal of the American Society for Information Science and Technology, New York, v. 53, n. 2, p. 145-161, 2002. 
RUÓTOLO, Antonio Carlos. Audiência e recepção: perspectivas.

Comunicação \& Sociedade, São Bernardo do Campo, n. 30, 1998. Disponível em: https://www.metodista.br/revistas/revistas-

ims/index.php/CSO/article/view/7875. Acesso em: 23 abr. 2020.

SILVA, Christiani Margareth de Menezes e. O conceito de doxa (opinião) em Aristóteles. Linha D'Água, São Paulo, v. 29, n. 2, p. 43-67, dez. 2016.

Disponível em: http://dx.doi.org/10.11606/issn.2236-4242.v29i2p43-67. Acesso em: 26 abr. 2020.

SPINK, Mary Jane P.; MEDRADO, Benedito. Produção de sentidos no cotidiano: uma abordagem teórico-metodológica para análise das práticas discursivas. In: SPINK, Mary Jane P. (org.). Práticas discursivas e produção de sentidos no cotidiano: aproximações teóricas e metodológicas. 2. ed. São Paulo: Cortez, 2000. cap. 2, p. 41-61.

STAHL, Bernd Carsten. On the difference or equality of information, misinformation, and disinformation: a critical research perspective. Informing Science, Santa Rosa, v. 9, p. 83-96, 2006. Disponível em: http://www.inform.nu/Articles/Vol9/v9p083-096Stahl65.pdf. Acesso em: 6 maio 2020.

VIANA, Nildo. As representações cotidianas e as correntes de opinião. Espaço Livre, v. 10, n. 19, p. 7-17, jan./jun. 2015. Disponível em:

https://redelp.net/revistas/index.php/rel/article/view/293. Acesso em: 25 abr. 2020.

WILSON, Tom D. Information behaviour: an interdisciplinary perspective.

Information Processing \& Management, Elmsford, v. 33, n. 4, p. 551-572, 1997.

WILSON, Thomas D. Human information behavior. Informing Science, Santa Rosa, v. 3, n. 2, p. 49-56, 2000.

\title{
DISINFORMATION AND INFORMATION BEHAVIOR IN SOCIAL MEDIA: SCIENCE COMMUNICATION FOR PREVENTION OF THE NOVEL CORONAVIRUS
}

\begin{abstract}
Introduction: The climate of insecurity about the Covid-19 pandemic, the lack of accurate information and the growing use of information and communication technologies seem to have contributed to promote the production and circulation of disinformation on social media. Objective: This study aimed to characterize the discursive practices associated with the "Vídeo do álcool gel no WhatsApp é mentira" and to identify expressions of information behavior in comments to the video. Methodology: Content analysis was chosen as research method due to the characteristics of empirical material and the focus on emerging meanings. Results: The results show ten discursive practices related to "Vídeo do álcool gel no WhatsApp é mentira", represented by the following categories: opining, mocking, reporting,
\end{abstract}


congratulating, thanking, asking, engaging, contributing, supporting and requesting. The opining category was the most expressive, with $50 \%$ of the units of analysis, suggesting that the formation of opinion or judgment on the published content is a relevant aspect for users. Expressions compatible with information seeking, information sharing, information evaluation and information use behavior were observed in the following categories: reporting, asking, engaging, contributing and requesting, as well as the praise, convergence and criticism subcategories. Conclusions: It is concluded that the characterization of the discursive practices expressed in the comments allowed the identification of information behavior in relation to the video and the ways of engaging with YouTube videos.

Descriptors: Disinformation. Information behavior. Science communication. Social media.

\title{
DESINFORMACIÓN Y COMPORTAMIENTO INFORMACIONAL EN REDES SOCIALES: DIVULGACIÓN CIENTÍFICA EN LA PREVENCIÓN DEL NUEVO CORONAVÍRUS
}

\begin{abstract}
RESUMEN
Introducción: El clima de inseguridad sobre la pandemia Covid-19, la falta de información precisa y el uso creciente de tecnologías de información y comunicación parecen haber contribuido a impulsar la producción y circulación de información engañosa en las redes sociales online. Objetivo: El presente estudio tuvo como objetivo caracterizar las prácticas discursivas asociadas al ao "Vídeo do álcool gel no WhatsApp é mentira" e identificar expresiones de comportamiento informacional en los comentarios al video. Metodología: Se eligió el análisis de contenido como método de investigación debido a las características del material empírico y al enfoque en los significados emergentes. Resultados: En el proceso de análisis se identificaron diez prácticas discursivas relacionadas con el ao "Vídeo do álcool gel no WhatsApp é mentira", representadas por las categorías opinar, ironizar, relatar, felicitar, agradecer, preguntar, involucrar, contribuir, apoyar y solicitar. La categoría opinar fue la más expresiva, con el $50 \%$ de las unidades de análisis, sugiriendo que la formación de opinión o juicio sobre el contenido publicado es un aspecto relevante para los usuarios. Se observaron expresiones compatibles con los comportamientos de buscar, compartir, evaluar y usar información en las categorías relatar, preguntar, involucrar, contribuir y solicitar, así como las subcategorías de elogio, convergencia y crítica. Conclusiones: Se concluye que la caracterización de las prácticas discursivas expresadas en los comentarios permitió identificar el comportamiento informacional en relación al video y las formas de relacionarse con el contenido publicado en YouTube.
\end{abstract}

Descriptores: Desinformación. Comportamiento informacional. Divulgación científica. Redes sociales online.

Recebido em: 27.08.2020

Aceito em: 22.02.2021 